\title{
Setor sucroenergético e estratégias microbiológicas para mitigação dos impactos ambientais da aplicação da vinhaça
}

No Brasil, a cana-de-açúcar tem sido usada como matéria-prima para a produção de etanol desde início do século XX, hoje a maioria das usinas de cana de açúcar produz além do etanol, açúcar e energia. A cadeia da cana-de-açúcar contribui de forma expressiva para o Produto interno Brasileiro (PIB) sendo o País o maior produtor mundial de etanol de cana-de-açúcar e sua produção deverá aumentar substancialmente nos próximos anos. No entanto, atrelado a expansão do setor surgem questões relacionadas com o aumento da geração de resíduos, como a vinhaça, gerada na etapa de destilação do caldo fermentado da cana-de-açúca para a obtenção do etanol. Este resíduo é comumente usado na fertirrigação, porém quando usado sem critérios técnicos pode acarretar impactos ambientais, como a salinização do solo e contaminação do lençol freático. Neste estudo, além das tecnologias usualmente empregadas em usinas de cana-de-açúcar para a aplicação da vinhaça no Brasil, foram levantadas informações sobre o potencial da vinhaça como meio do cultivo de microrganismos e as possíveis alterações químicas desse resíduo após inoculação. As pesquisas apontaram a capacidade do desenvolvimento e crescimento de microrganismos e microalgas na vinhaça, observando as variações na caracterização química, bem como a possível diminuição da carga poluidora. A divulgação dessas informações tecnológicas amplia as alternativas para descarte dos grandes volumes de vinhaça gerados pelas agroindústrias.

\section{Sugarcane industry and microbiological strategies to mitigate the environmental impacts of vinasse application}

\begin{abstract}
In Brazil, sugar cane has been used as a raw material for the production of ethanol since the beginning of the 20th century, today most sugarcane plants produce in addition to ethanol, sugar and energy. The sugarcane chain contributes significantly to the Gross Domestic Product (GDP), the country being the world's largest producer of ethanol from sugarcane and its production is expected to increase substantially in the coming years. However, linked to the expansion of the sector arise issues related to the increase of waste generation, such as vinasse, generated in the stage of distillation of the sugarcane fermented juice to obtain ethanol. This residue is commonly used in fertirrigation, but when used without technical criteria can lead to environmental impacts, such as salinization of the soil and contamination of the water table. In this study, in addition to the technologies usually employed in sugarcane mills for the application of vinasse in Brazil, information was collected on the potential of vinasse as a medium for the cultivation of microorganisms and the possible chemical changes of this residue after inoculation. The researches pointed out the capacity of the development and growth of microorganisms and microalgae in the vinasse, observing the variations in the chemical characterization, as well as the possible reduction of the polluting load. The dissemination of this information technologies broadens the alternatives for discarding the large volumes of vinasse generated by agroindustries.
\end{abstract}

Keywords: Bioethanol; Sugar Cane; Sustainability; Wastewater.

Topic: Desenvolvimento, Sustentabilidade e Meio Ambiente

Reviewed anonymously in the process of blind peer.
Received: 02/12/2018

Approved: 26/01/2019
Francielli Gasparotto (iD

Centro Universitário de Maringá, Brasil

http://lattes.cnpq.br/2673470812353146

http://orcid.org/0000-0002-4038-7364

francipg@gmail.com

Marcelo Teixeira Silva

Centro Universitário de Maringá, Brasil

http://lattes.cnpq.br/3090845425253198

http://orcid.org/0000-0002-6771-3254

teixeirasilvamarcelo82@gmail.com

\section{Aline Yukie Minasse Watanabe}

Centro Universitário de Maringá, Brasil

http://lattes.cnpq.br/5867084618062126

alinewatanabe8@gmail.com

\author{
Guilherme Miglioli Martins \\ Centro Universitário de Maringá, Brasil \\ http://lattes.cnpq.br/2623775419522205 \\ guil.miglioli@gmail.com \\ Cleiltan Novais da Silva \\ Centro Universitário de Maringá, Brasil \\ http://lattes.cnpq.br/9993910421974160 \\ http://orcid.org/0000-0002-6194-1950 \\ cleiltan@gmail.com \\ Edison Schmidt Filho \\ Centro Universitário de Maringá, Brasil \\ http://lattes.cnpq.br/7605628504842582 \\ http://orcid.org/0000-0001-9727-5024 \\ edison.schmidt@unicesumar.edu.br
}

Referencing this:

GASPAROTTO, F.; SILVA, M. T.; WATANABE, A. Y. M.; MARTINS, G. M.; SILVA, C. N.; SCHMIDT FILHO, E.. Setor sucroenergético e estratégias microbiológicas para mitigação dos impactos ambientais da aplicação da vinhaça. Revista Ibero Americana de Ciências Ambientais, v.10, n.1, p.241-251, 2019. DOI: http://doi.org/10.6008/CBPC21796858.2019 .001 .0020 


\section{INTRODUÇÃO}

No Brasil o setor agroindustrial da cana de açúcar é considerado um dos mais antigos e sempre esteve ligado com os principais eventos históricos do país. Este setor responsável pela produção de açúcar e biocombustível tem sido um dos mais importantes e estratégicos da economia brasileira. Ademais, o Brasil ocupa lugar de destaque no cenário mundial, como o maior exportador de açúcar e maior produtor de etanol derivado da cana-de-açúcar. No entanto, o aumento da produção de bioetanol levou ao aumento da geração de resíduos, com destaque para a vinhaça, gerada na etapa de destilação subsequente à fermentação de carboidratos obtidos de diferentes fontes de sacarídeos, neste caso da cana-de-açúcar (WILKIE et al., 2000).

Nas usinas brasileiras, para cada litro de etanol produzido, são gerados, em média, 13,7 litros de vinhaça (CAVALETT et al., 2012). Considerando uma produção de aproximadamente 27,7 bilhões de litros de etanol na safra 2017/18 (CONAB, 2018), estima-se que a produção média de vinhaça foi de aproximadamente 379 bilhões de litros.

O destino da vinhaça representa um dos principais ônus da indústria sucroalcooleira no Brasil (FUESS et al., 2018), apresentando como principais características o pH ácido $(4,3)$ e a alta demanda química de oxigênio (DQO $23.801 \mathrm{mg} \mathrm{L}^{-1}$ ), podendo causar impacto cem vezes maior que o esgoto doméstico (SEIXAS et al., 2016). O potássio (k), nitrogênio (N), cálcio (Ca) e magnésio (Mg) são os principais componentes químicos da vinhaça, sendo $\mathrm{K}$ o elemento mineral mais importante, justificando o uso agrícola do resíduo (PRADO et al., 2013).

Devido às características apresentadas, combinadas com o alto volume de produção, a disposição adequada do resíduo torna-se necessária. No Brasil, a vinhaça é comumente aplicada no solo como fertilizante para a cultura da cana de açúcar devido aos seus altos níveis de matéria orgânica e nutrientes (especialmente K, mas também N e P) (NASPOLINI et al., 2017), sendo disponibilizada para a cultura em sua condição original (CRUZ et al., 2013).

Embora estudos tenham associado resultados benéficos à fertirrigação (SILVA et al., 2007; BARROS, 2012), incluindo redução de gastos com fertilizantes inorgânicos, a disposição da vinhaça no solo, pode gerar impactos negativos para o sistema solo-água-planta a longo prazo (FUESS et al., 2014; OLIVEIRA et al., 2013), como a salinização do solo e a subsequente desestabilização estrutural do terreno, perdas de atividade microbiana e a acidificação dos solos (FUESS et al., 2018), lixiviação de nitratos do solo (PARNAUDEAU et al., 2008), contaminação de águas superficiais (GUNKEL et al., 2007). Além disso, deve ser considerado o agravamento do aquecimento global pela liberação de óxido nitroso $\left(\mathrm{N}_{2} \mathrm{O}\right)$ na desnitrificação heterotrófica do solo (PAREDES et al., 2015).

Ainda que as perspectivas econômicas apontem a fertirrigação como uma solução simples e de baixo custo para o descarte de vinhaça em abundância (PRADO et al., 2013; ORTEGÓN et al., 2016). Tecnologias complementares devem ser pesquisadas a fim de mitigar os impactos negativos da fertirrigação em longo prazo. Neste contexto, estudos relacionados com uso de vinhaça como meio de cultivo para microrganismos 
têm sido relatados, uma vez que alguns organismos podem produzir subprodutos de valor agregado e também reduzir a carga poluidora desse resíduo (CAZETTA et al., 2005).

De fato, pesquisas constataram que microalgas se adaptam bem na vinhaça como meio de crescimento, por conter água e nutrientes necessários para seu desenvolvimento (SEREJO, 2010; CHRISTENSON et al., 2011). A vinhaça como substrato promoveu a multiplicação e desenvolvimento da bactéria Bacillus subtilis (CARDOZO et al., 2011). Além disso, a vinhaça foi utilizada no cultivo da cianobactéria Aphanothece microscopica e a Chlorella vulgaris (BONINI, 2012) e fungos Pleurotus sajor-caju sendo capazes de reduzir os componentes poluentes do efluente (FERREIRA, 2009).

Diante do exposto, o presente trabalho de revisão visou identificar formas alternativas para o uso da vinhaça, como potencial meio do cultivo para microrganismos e subprodutos de valor agregado e possíveis alterações químicas desse resíduo após sua inoculação, culminado com a possibilidade de diminuição da carga poluidora, abordando as principais questões de sustentabilidade associadas às consequências ambientais do cultivo de cana-de-açúcar no Brasil.

\section{METODOLOGIA}

O estudo trata-se de uma revisão narrativa ou tradicional, pois apresenta uma temática mais aberta (CORDEIRO et al., 2007). O presente trabalho foi realizado por meio de um levantamento bibliográfico mediante consulta às bases de dados on line, principalmente de revista indexadas, tais como: scielo, web of Science, além de teses e dissertações. Foram selecionados artigos escritos em inglês, português ou espanhol.

$\mathrm{Na}$ busca de artigos, foram utilizados, os seguintes descritores e suas combinações na língua portuguesa e inglesa respectivamente: cana-de-açúcar, sugar cane, fertirrigação, fertigation, meio de cultivo, culture médium, microrganismos, microorganisms, mitigação, mitigation, tratamento de efluente, wastewater treatment, vinhaça, vinasse. Os critérios de inclusão para a seleção de artigos foram às combinações de palavras acima, relacionadas com alternativas de uso e mitigação dos impactos da vinhaça.

\section{DISCUSSÃO TEÓRICA}

\section{Sustentabilidade no setor sucroenergético}

O tripé da sustentabilidade (do inglês Triple Bottom Line) baseia-se principalmente na necessidade de conciliar crescimento econômico com equidade social e preservação ambiental, ou seja, maior produção com menor geração de resíduos e consumo de energia, consequentemente, maior eficiência ambiental (HEPPER et al., 2017)

Dentro deste contexto, os efeitos sociais do setor sucroenergético se alicerçam na geração de aproximadamente 950 mil empregos diretos, que somados aos indiretos totalizam cerca de três milhões de empregos. O número de produtores independentes de cana de açúcar é também expressivo, aproximandose de 70 mil em todo o Brasil. Com faturamento na ordem de 80 bilhões de reais, a cadeia produtiva da cana- 
de-açúcar enquadra-se como o 4ํㅗ segmento na pauta de exportação do agronegócio brasileiro (ASSAD, 2017).

Dentre os produtos do setor sucroenergético, o etanol tem merecido destaque como uma alternativa para reduzir a emissão de gases causadores do efeito estufa. Haja vista, que a sua queima como combustível reduz cerca de $70 \%$ a emissão de $\mathrm{CO}_{2}$ na atmosfera quando comparado à gasolina, gerando vantagens ambientais. Desde 2003, data que coincide com o lançamento da tecnologia flex no Brasil, houve uma redução de 350 milhões de toneladas de $\mathrm{CO}_{2}$ eq lançadas na atmosfera, volume comparado, às emissões anuais da Polônia, uma das principais nações poluidoras do mundo.

O setor sucroalcooleiro apresenta vários subprodutos, entre eles o bagaço da cana-de-açúcar. No início, o bagaço era utilizado como combustível substituto à lenha, porém, a partir do século XXI, seu principal aproveitamento ocorre no processo de produção de energia (térmica e elétrica), conhecido como cogeração (SOUZA et al., 2006).

Além das vantagens relacionadas com a geração de renda, estímulos à indústria de bens de capital e poupança de divisas, a bioeletricidade traz benefícios ambientais em relação às usinas termoelétricas que são movidas a combustíveis fósseis. Deste modo, a bioeletricidade oriunda do bagaço da cana destaca-se como uma alternativa na diversificação da matriz elétrica brasileira, com capacidade de suprir a demanda energética durante o período de estiagem das hidroelétricas, mantendo a competitividade da economia nacional (ZAZYKI et al., 2016).

\section{O setor sucroenergético no Brasil}

No Brasil, a cadeia agroindustrial da cana de açúcar é considerada uma das mais antigas e sempre esteve ligada com os principais eventos históricos do país (FARINA, 1998). A cana de açúcar foi introduzida no Brasil em 1532 e sempre teve importância destacada na economia. O país não é só o maior produtor mundial da cultura, seguido por Índia e China, mas também é o maior produtor mundial de açúcar e etanol derivados da cana-de-açúcar.

O Brasil é referência nos estudos sobre cana-de-açúcar, reflexo de anos de experiência que teve início nos anos 70 com a criação do Proálcool (Programa Nacional do Álcool). No período em que ocorreu a crise mundial do petróleo, especificamente em 1973, o Brasil importava cerca de 80 \% do petróleo consumido no país, sendo assim, o governo iniciou uma série de ações como investimentos no setor sucroenergético com intuito de reduzir a importação e consumo de diesel (VIEIRA et al., 2007).

A partir do incentivo ao programa Proálcool, houve um crescimento na produção de etanol e consequente a quantidade de vinhaça, resíduo oriundo da destilação do etanol, crescia ao mesmo ritmo que a produção de etanol, desta forma, as consequências de sua deposição no meio ambiente começaram a se tornar mais aparentes. Neste sentido, começaram a surgir estudos sobre as possibilidades ambientalmente corretas para sua disposição (SILVA, 2012). O Brasil vem ao longo de anos produzindo etanol em grande escala para combustível automotivo. O país é o segundo maior produtor mundial de etanol e é o único país onde os biocombustíveis competem com a gasolina. 
Na safra $2017 / 2018$ onde foram produzidos aproximadamente 27,7 bilhões de litros de etanol (CONAB, 2018), estimou-se a geração de aproximadamente 379 bilhões de litros de vinhaça. Assim, o setor sucroenergético brasileiro destaca-se no cenário agrícola, porém atrelado ao avanço na produção, grandes quantidades de resíduos tem sido gerando, entre estes a vinhaça pode ser considerada um dos mais preocupantes (ROLIM et al., 2013).

\section{Vinhaça}

A vinhaça é um resíduo inerente do processo produtivo do etanol, e, para cada litro do biocombustível produzido, 10 a 18 litros são produzidos de vinhaça (CHRISTOFOLETTI et al., 2013). No final dos anos 70 o lançamento de vinhaça nos mananciais superficiais era realizado de acordo com a produção de etanol, causando assim impactos ambientais agudos e pontuais em virtude da sazonalidade da disposição. Desta forma, a opção encontrada na época foram as chamadas áreas de sacrifício, basicamente grandes áreas onde era depositada a vinhaça, porém estas áreas tornavam-se inutilizadas com o passar do tempo (SILVA, 2011).

A aplicação de vinhaça no solo atualmente ocorre por meio da fertirrigação, um processo que engloba desde sua geração passando pelo sistema de armazenamento, geralmente composto por lagoas, em seguida a vinhaça é distribuída por canais até o local da aplicação (PAREDES, 2015). A vinhaça representa um grande problema para o setor sucroenergético devido ao grande volume produzido e ao seu alto teor poluente, principalmente em função da sua elevada concentração de matéria orgânica recalcitrante (PRADO et al., 2013; SYDNEY et al., 2014; COLIN et al., 2016).

Em função das suas características físico-químicas, a vinhaça é geralmente utilizada como fertilizante, apresentando algumas vantagens em termos de crescimento e produtividade da cana (SYDNEY et al., 2014). O resíduo é um líquido de odor forte, coloração marrom-escuro, baixo $\mathrm{pH}$, alto teor de potássio e com alta demanda química de oxigênio (DQO), ou seja, alta carga de matéria orgânica, tornando-se assim um material altamente poluidor (SILVA et al., 2014). A preocupação em relação à geração e disposição da vinhaça emergiu, principalmente, porque quando o resíduo não é destinado corretamente pode contribuir para a contaminação de rios, lagos e solos (ZOLIN et al., 2011).

A composição da vinhaça é principalmente por elementos químicos como manganês ( $\mathrm{Mn}$ ), cobre $(\mathrm{Cu})$, zinco $(\mathrm{Zn})$, ferro $(\mathrm{Fe})$, enxofre $(\mathrm{S})$, magnésio $(\mathrm{Mg})$, cálcio $(\mathrm{Ca})$, fósforo $(\mathrm{P})$, nitrogênio $(\mathrm{N})$, carbono $(\mathrm{C})$, e, principalmente potássio $(K)$ podendo substituir fertilizantes químicos na produção de cana. Porém, a quantidade de cada elemento é variável em função do sistema de produção e da variedade da cana-de-açúcar (OLIVEIRA et al., 2012).

Barros et al. (2010) observaram, em seus estudos que a utilização de vinhaça durante 10 anos, acarretou melhoria da disponibilidade dos macronutrientes (N, P, K) e inversamente em função da elevação do pH houve diminuição da disponibilidade dos micronutrientes. Otto et al. (2010) verificaram que ao trabalhar com o manejo da adubação potássica com origem na vinhaça ocorreram na cultura da cana-deaçúcar efeitos positivos na altura das plantas, perfilhamento e na produção de colmos atribuídos ao potássio, 
tanto em aplicação única de vinhaça ou também na forma parcelada. Já Vasconcelos et al. (2010) observaram que ocorreu elevação do limite da consistência do solo, reduzindo o risco da deformação plástica e também o aumento do carbono orgânico total do solo, pelo uso da vinhaça.

Por outro lado, estudos têm demonstrado que irrigar culturas com vinhaça poderia levar à contaminação de água subterrânea através de infiltração (RAMIREZ et al., 2014). Este impacto negativo está associado à poluição/contaminação do lençol freático, tendo em vista que ao se infiltrar ocorre o arraste dos componentes da vinhaça na recarga dos aquíferos (OLIVEIRA, 2011). A agricultura irrigada é consumidora de grandes quantidades de água, assim se faz necessário o aproveitamento da vinhaça como forma de irrigação e complementação hídrica da cultura da cana-de-açúcar proporcionando maior produtividade, porém a preservação do meio ambiente deve ser considerada.

Outro uso da vinhaça consiste na transformação da matéria orgânica presente na vinhaça em biogás por meio da ação de microrganismos. O biogás é composto principalmente por metano, dióxido de carbono e outros gases em pequenas quantidades. Após a adequação, o biogás pode ser utilizado para geração de energia elétrica ao movimentar a turbina de um gerador. Consequentemente, a produção de biogás minimiza o impacto ambiental do uso desse resíduo como fertilizante na cultura da cana-de-açúcar, uma vez que após a digestão da vinhaça ocorre a redução de matéria orgânica (SILVEIRA, 2015).

\section{Cultivo de microrganismos em vinhaça}

É crescente o interesse pelo desenvolvimento de microrganismos como leveduras, algas, fungos e bactérias em substratos de efluentes industriais tais como soro de leite, glutamato, material celulósico de origem vegetal e a vinhaça (CAZETTA et al., 2005). A utilização desses microrganismos pode gerar subprodutos de valor agregado e também reduzir a carga poluidora do resíduo (ROSSOL et al., 2012).

Trabalhos constataram que microalgas se adaptam bem na vinhaça como meio de crescimento, por esta conter água e nutrientes necessários para seu desenvolvimento (CHRISTENSON et al., 2011). Os autores verificaram também que uma maior produção de biomassa, teoricamente, pode ser obtida a partir da utilização da vinhaça, baseado na fórmula da biomassa gerada por algas $\mathrm{C}_{106} \mathrm{H}_{181} \mathrm{O}_{45} \mathrm{~N}_{16} \mathrm{P}$.

Candido et al. (2016) também relataram que é possível utilizar a vinhaça tratada como meio de cultivo de microalgas. $O$ estudo demonstrou, em escala laboratorial, que a utilização da vinhaça pode reduzir o custo de produção de microalgas e proporcionar um tratamento da vinhaça, como aumento do pH, redução de nitrogênio e potássio, resultando então em menor degradação ambiental, quando aplicada no solo.

A melhora das características da vinhaça também foi verificada por Bonini et al. (2012) com o cultivo da cianobactéria Aphanothece microscópica e de Chlorophyceae Chlorella vulgaris ocorrendo à redução do DQO dos meios. Além destes microrganismos, vários estudos avaliaram o crescimento de fungos utilizando a vinhaça como meio de cultivo. O cultivo da espécie fúngica Pleurotus sajor-caju em vinhaça com concentração de $100 \%$, resultou em maior quantidade de biomassa do microrganismo, além da redução dos poluentes da vinhaça no processo de fermentação (FERREIRA, 2009). 
No mesmo sentido, Sartori et al. (2015) avaliaram o cultivo dos fungos Pleurotus sajor-caju, $P$. ostreatus, P. albidus e P. flabellatus na vinhaça visando a produção destes como fonte de alimento para peixes do gênero Danio rerio em piscicultura. Como resultados os autores concluíram que houve crescimento satisfatório dos fungos e os valores nutricionais foram similares com as rações comercializadas. Não houve toxicidade nos peixes alimentados com os fungos analisados, indicando então que é possível utilizar a vinhaça como meio de cultivo para esses fungos utilizados como fonte de alimentos.

A vinhaça foi utilizada por Oliveira et al. (2012) como fonte inibidora do cádmio e níquel em Saccharomcyces cerevisiae. Segundo os pesquisadores, as leveduras podem ser utilizadas como forma acessível de mitigar impactos causados pela poluição por metais, já que em sua estrutura é possível acumular esses poluentes, porém alguns metais podem ser tóxicos as estruturas das leveduras. A vinhaça então atua como protetor dos efeitos negativos dos metais, especificamente do cádmio e níquel. O estudo mostrou aplicabilidade do subproduto da indústria de etanol, sendo uma forma acessível economicamente de sanar problemas ligados à toxicidade por metais.

Outro grupo microbiano que apresenta estudos de cultivo em vinhaça são as bactérias. Cardozo et al. (2011) em seus estudos observaram a capacidade do desenvolvimento da espécie bacteriana Bacillus subtilis em diversas diluições de vinhaça, verificando-se que na concentração de $25 \%$, ocorreu o maior crescimento bacteriano.

Da mesma forma, Aparicio et al. (2017) utilizaram vinhaça bruta em diferentes concentrações como meio de cultivo na produção de biomassa de actinobactérias. Esses microrganismos são utilizados como biorremediadores de solos contaminados e concluiu-se que o uso de aproximadamente 10.000 a $12.000 \mathrm{~L}$ de vinhaça produziria a biomassa necessária para o tratamento de $10.000 \mathrm{~m}^{2}$ de solo contaminado. Além disso, o estudo demonstrou uma redução da DBO em torno de $50 \%$. Assim, com este cultivo é possível reduzir os custos de produção de biomassa bacteriana e melhorar a DBO da vinhaça.

Ademais, alguns processos de aproveitamento da vinhaça e bagaço de cana como meio de cultivo de microrganismos visam a produção de enzimas, a exemplo de bactérias e fungos que sintetizam bioenzimas que degradam material lignocelulósicos (HOARAUA et al., 2018). Além disso, a biomassa gerada na vinhaça ou mesmo presente no bagaço de cana, podem ser degradadas por meio de reações enzimáticas produzidas por fungos que tem a capacidade de metabolizar longas cadeias poliméricas que compõem os mais importantes componentes da biomassa como celulose, hemicelulose e lignina, transformando em açúcares fermentáveis produzindo bioetanol de segunda geração e outros produtos (HORTA et al., 2018).

Outro produto de valor agregado, obtido a partir da vinhaça está associada à obtenção de ácidos orgânicos cujo interesse comercial é crescente a nível mundial, devido às várias possibilidades de usos na indústria (HOARAUA et al., 2018). A vinhaça possui em sua composição altos teores de proteínas, aproximadamente $8 \%$ de lipídios, além de ser considerada uma fonte mineral, o que torna possível o cultivo de lactobacilos como Lactobacillus rhamnosus, que produz ácido lático utilizado como subproduto ração para alimentação animal o que torna esse processo mais sustentável (VUKOVIĆ et al., 2015) 
Adicionalmente, os microrganismos atuam na digestão anaeróbia removendo parte da matéria orgânica e elevando o pH da vinhaça, enquanto que mantém os nutrientes deste resíduo praticamente inalterados. Assim, a vinhaça digerida anaerobiamente pode ser utilizada como uma fonte de custo baixo de macro e micronutrientes para o cultivo de microalgas na produção de biomassa, consequentemente, gerar energia elétrica (SEREJO, 2010).

Ferraz-Junior et al. (2014) alimentaram um sistema de reator anaeróbio de leito fixo com vinhaça e concluíram que as bactérias Thermoanaerobacterium thermosaccharolyticum produziram no sistema uma grande quantidade de hidrogênio utilizando a vinhaça da cana-de-açúcar como substrato em condição termofílica. Além da produção de hidrogênio, o resíduo pode ser utilizado em biodigestores, ou seja, é possível realizar produção de biogás. Silva et al. (2017) aproveitaram as características favoráveis da vinhaça na produção de biogás e investigaram a influência da quantidade de esterco (inóculo) durante um processo de biodigestão, comportamento de parâmetros da vinhaça (físicos-químicos), sanidade do lodo remanescente no digestor e a produção de metano.

Os autores acima observaram que após um tempo de detenção hidráulica (TDH) de 20 dias, houve estabilização do pH e produção de biogás, com $70 \%$ de metano em sua composição. Houve remoção da DQO de $67 \%$ e de sólidos totais de $40 \%$, porém os teores de nitrogênio e fósforo foram preservados, resultado interessante para a aplicação do biofertilizante. E ainda ocorreu a estabilização do lodo, removendo 90 a $95 \%$ de coliformes totais e fecais. Em relação à maior quantidade de inóculo adicionado, não houve melhoria da eficiência na produção de biogás, concluindo então que é possível utilizar quantidades menores.

\section{CONCLUSÕES}

Diante do crescimento do setor sucroenergético brasileiro, este trabalho relatou alternativas para o tratamento da vinhaça ou do seu uso como substrato para produção de compostos de valor agregado a partir da inoculação de microrganismos com potencial biotransformador. As informações disponibilizadas sobre possibilidades para a destinação da vinhaça poderão ser utilizadas culminando com a mitigação dos impactos ambientais causados no setor.

\section{REFERÊNCIAS}

APARICIO, J. D.; BENIMELI, C. S.; ALMEIDA, C. A.; POLTI, M. A.; COLIN, V. L.. Integral use of sugarcane vinasse for biomass production of actinobacteria: Potential application in soil remediation. Chemosphere, v.181, p.478-484, 2017. DOI: http://doi.org/10.1016/j.chemosphere.2017.04.107

ASSAD, L.. Aproveitamento de resíduos do setor sucroalcooleiro desafia empresas e pesquisadores. Ciência e Cultura, v.69, n.4, 2017. DOI:

http://dx.doi.org/10.21800/2317-66602017000400005

BARROS, R. P.. Diversidade de fungos em um vertissolo com adição de vinhaça na cultura de cana de açúcar (Saccharum officinarum). Revista Uniabeu, v.5, n.10, p.181-196, 2012.
BARROS, R. P.; VIÉGAS, P. R. A.; SILVA, T. L.; SOUZA, R. M.; BARBOSA, L.; VIÉGAS, R. A.; BARRETTO, M. C. V.; MELO, A. S.. Alterações em atributos químicos de solo cultivado com cana-de-açúcar e adição de vinhaça. Pesquisa Agropecuária Tropical, v.40, p.341-346, 2010.

BONINI, M. A.; BASTOS R. G.. Produção de biomassa de Aphanothece microscopica e Chlorella vulgaris por cultivo heterotrófico a partir de Glicose. Semina: Ciências Biológicas e da Saúde, v.33, n.2, p.151-160, 2012. DOI: http://doi.org/10.5433/1679-0367.2012v33n2p151

CANDIDO, C.; LOMBARDI, A. T.. Growth of Chlorella vulgaris in treated conventional and biodigested vinasses. Journal of applied Phycology, v29, p.45-53, 2016. DOI: http://doi.org/10.1007/s10811-016-0940-2 
CARDOZO, R. B.; ARAUJO, F. F.. Multiplicação de Bacillus subtilis em vinhaça e viabilidade no controle da meloidoginose, em cana-de-açúcar. Revista Brasileira de Engenharia Agrícola e Ambiental, v.15, n.12, p.1283-1288., 2011. DOI: http://doi.org/10.1590/S141543662011001200010

CORDEIRO, A. M.; OLIVEIRA, G. M.; RENTERÍA, J. M.; GUIMARÃES, C. A.. Revisão sistemática: uma revisão narrativa. Revista do Colégio Brasileiro de Cirurgiões, v.34, n.6, p.428-431, 2007. DOI: http://doi.org/10.1590/s0100$\underline{69912007000600012}$

CAVALETT, T. L.; JUNQUEIRA, M. O. S.; DIAS, M. O. S.; JESUS, C. D. F.; MANTELATTO, P. E.; CUNHA, M. P.; FRANCO, H. C. J.; CARDOSO, T. F.; MACIEL FILHO, R.; ROSSELL, C. E. V.; BONOMI, A.. Environmental and economic assessment of sugarcane first generation biorefineries in Brazil. Clean Technologies and Environmental Policy, v.14, n.3, p.399410, 2012. DOI: http://doi.org/10.1007/s10098-011-0424-7

CAZETTA L. M.; CELLIGOI, M. A. P. C.. Aproveitamento do melaço e vinhaça de cana-de-açúcar como substrato para produção de biomassa proteica e lipídica por leveduras e bactéria. Semina: Ciências Exatas e Tecnológicas, v.26, n.2, p.105-112, 2005.

CHRISTENSON, L.; SIMS, R.. Production and Harvesting of Microalgae for Wastewater Treatment, Biofuels, and Bioproducts. Biotechnology Advances, v.29, n.6, p.686-702, 2011. DOI: http://doi.org/10.1016/j.biotechadv.2011.05.015

CHRISTOFOLETTI, C. A.; ESCHER, J. P.; CORREIA, J. E.; MARINHO, J. F. U.; FONTANETTI, C. S.. Sugarcane vinasse: Environmental implications of its use. Waste Management, v.33, n.12, p.2752-2761, 2013. DOI: http://doi.org/10.1016/j.wasman.2013.09.005

COLIN, V. L.; CORTEZ, A. A. J.; APARICIO, J. D.; AMOROSO; M. J.. Chemosphere Potential application of a bioemulsifierproducing actinobacterium for treatment of vinasse. Chemosphere, v.144, p.842-847, 2016. DOI: http://doi.org/10.1016/j.chemosphere.2015.09.064

CONAB. Companhia Nacional de Abastecimento. Acompanhamento da safra Brasileira de cana-de-açúcar: safra 2016-2017. 2018.

CRUZ, L. F. L. S.; DUARTE, C. G.; TADEU, F. M.; PIRES, E. C.. Análise da viabilidade técnica, econômica e ambiental das atuais formas de aproveitamento da vinhaça: fertirrigação, concentração e biodigestão. Revista Brasileira de Ciências Ambientais, n.29, p.111-127, 2013.

\section{FARINA, E. M. M. Q.. Competitividade Do Sistema} agroindustrial Da Cana-de-açúcar. v.5. São Paulo: IPEA,1998.

FERRAZ JUNIOR, A. D. N.; WENZEL, J.; ETCHEBEHERE, M. Z.. Effect of organic loading rate on hydrogen production from sugarcane vinasse in thermophilic acidogenic packed bed reactors. International Journal of Hidrogen Enerngy, v.39, p.16852-16862, 2014. DOI: http://dx.doi.org/10.1590/0103$\underline{8478 \mathrm{cr} 20160957}$

FERREIRA, L. F. R.. Biodegradação de vinhaça proveniente do processo industrial de cana-de-açúcar por fungos. 2009.
Tese (Doutorado em Microbiologia Agrícola) - Universidade de São Paulo, Piracicaba, 2009.

FUESS, L. T.; GARCIA, M. L.; ZAIATA, M.. Seasonal characterization of sugarcane vinasse: Assessing environmental impacts from fertirrigation and the bioenergy recovery potential through biodigestion. Science of The Total Environment, v.634, p.29-40, 2018. DOI: http://doi.org/10.1016/j.scitotenv.2018.03.326

FUESS, L. T.; GARCIA, M. L.. Implications of stillage land disposal: a critical review on the impacts of fertigation. Journal of Environmental Management, v.145, p.210-229, 2014. DOI: http://doi.org/10.1016/j.jenvman.2014.07.003

GUNKEL, G.; KOSMOL, J.; SOBRAL, M.; ROHN, H.; MONTENEGRO, S.; AURELIANO, J.. Sugar cane industry as a source of water pollution - Case study on the situation in Ipojuca river, Pernambuco, Brazil. Water, Air, \& Soil Pollution, v.180, n.1-4, p.261-269, 2007. DOI: http://doi.org/10.1007/s11270-006-9268-x

HEPPER, E. L.; SOUZA, O. T.; PETRINI, M. C. E. S.; LOBO, C. E. E.. Proposição de um modelo de maturidade para sustentabilidade corporativa. Acta Scientiarum, Human and Social Sciences, v.39, n.1, p.43-53, 2017. DOI: http://dx.doi.org/10.4025/actascihumansoc.v39i1.33127

HOARAUA, J.; CAROA, B. Y.; GRONDINA, I.; PETIT, T. Sugarcane vinasse processing: Toward a status shift from waste to valuable resource. Journal of Water Process Engineering, v.24, p.11-25, 2018. DOI: http://doi.org/10.1016/j.jwpe.2018.05.003

HORTA, M. A. C.; FERREIRA FILHO, J. A.; MURAD, N. F.; SANTOS, E. O.; SANTOS, C. A.; MENDES, J. S.; BRANDÃO, M. M.; AZZONI, S. F.. Network of proteins, enzymes and genes linked to biomass degradation shared by Trichoderma species. Scientific Reports, v.8, n.1341, p.1-11, 2018. DOI: http://doi.org/10.1038/s41598-018-19671-w

NASPOLINI, B. F.; MACHADO, A. C. O.; CRAVO JR, W. B.; FREIRE, D. M. G.; CHRISTE, M.. Bioconversion of Sugarcane Vinasse into High-Added Value Products and Energy. BioMed Research International, v.2017, p.1-11, 2017. DOI: http://doi.org/10.1155/2017/8986165

OLIVEIRA, A. L. M.; COSTA, K. R.; FERREIRA, D. C.; MILANI, K. M. L.; SANTOS, O. J. A. P.; SILVA, M. B.; ZULUAGA, M. Y. A.. Biodiversity of soil bacteria and its applications for a sustainable agriculture. Biochemistry and biotechnology reports, v.3, n.1, p.56-77, 2014. DOI: http://doi.org/10.5433/2316-5200.2014v3n1p56

OLIVEIRA, B. G.; CARVALHO, J. L. N.; CERRI, C. E. P.; CERRI, C. C.; FEIGL, B. J.. Soil greenhouse gas fluxes from vinasse application in Brazilian sugarcane areas. Geoderma, v.200201, p.77-84, 2013. DOI:

http://dx.doi.org/10.1016/j.geoderma.2013.02.005

OLIVEIRA, R. P. S.; BASSO, L. C.; PESSOA JUNIOR, A. P.; PENNA, T. C. V.; DEL BORGHI, M.; CONVERTI, A.. Response of Saccharomyces cerevisiae to Cadmium and Nickel Stress: The Use so the Sugar Cane Vinasse as a Potential Mitigator. Biological Trace Element Research, v.145, p.71-80, 2012. DOI: http://doi.org/10.1007/s12011-011-9156-0 
OLIVEIRA, W. S.; BRITO, M. E. B.; ALVES, R. A. B.; SOUZA, A. S.; SILVA, E. G.. Cultivo da cana-de-açúcar sob fertirrigação com vinhaça e adubação mineral. Revista Verde, v.9, n.1, p.01-05, 2014.

ORTEGÓN, G. P.; ARBOLEDA, F. M.; CANDELA, L.; TAMOH, K.; VALDES-ABELLAN, J.. Vinasse application to sugar cane fields. Effect on the unsaturated zone and groundwater at Valle del Cauca (Colombia). Science of The Total Environment, v.539, p.410-419, 2016. DOI: http://doi.org/10.1016/j.scitotenv.2015.08.153

OTTO, R.; VITTI, G. C.; LUZ, P. H. C.. Manejo da adubação potássica na cultura da cana-de-açúcar. Revista Brasileira de Ciência do Solo, v.34, n.4, p.1137-1145, 2010. DOI: http://dx.doi.org/10.1590/S0100-06832010000400013

PAREDES, D. D. S.; ALVES, B. J. R.; SANTOS M. A.; BOLONHEZI, D.; SANT'ANNA, S. A. C.; URQUIAGA, S.; LIMA, M. A.; BODDEY, R. M.. Nitrous Oxide and Methane Fluxes Following Ammonium Sulfate and Vinasse Application on Sugar Cane Soil. Environmental Science \& Technology, v.49, n.18, p.11209-11217, 2015. DOI: http://doi.org/10.1021/acs.est.5b01504

PARNAUDEAU, V.; CONDOM, N.; OLIVER, R.; CAZEVIEILLE, P.; RECOUS, S.. Vinasse organic matter quality and mineralization potential, as influenced by raw material, fermentation and concentration processes. Bioresource Technology, v.99, n.6, p.1553-1562, 2008. DOI: http://doi.org/10.1016/j.biortech.2007.04.012

PRADO, R. D. M.; CAIONE, G.; CAMPOS, C. N. S.. Filter Cake and Vinasse as Fertilizers Contributing to Conservation Agriculture. Applied and Environmental Soil Science, v.2013, p.8, 2013. DOI:

http://dx.doi.org/10.1155/2013/581984

RAMIREZ, N. N. V.; FARENZENA, M.; TRIERWEILER, J. O.. Growth of Microalgae Scenedesmus sp in Ethanol Vinasse. Braz. Arch. Biol. Technol, v.57, n.5, p.630-635, 2014. DOI: http://dx.doi.org/10.1590/S1516-8913201401791

ROLIM, M. M.; LYRA, M. R. C. C.; DUARTE, A. S.; FERNANDES, M. P. R.; SILVA, Ê. F. F.; PEDROSA, E. M. R.. Influência de uma lagoa de distribuição de vinhaça na qualidade da água freática. Revista Ambiente \& Água, v.8, n.1, p.155-171, 2013. DOI: http://doi.org/10.4136/ambi-agua.1014

ROSSOL, C. D.; SCALON, F. H.; BERTÉ, L. N.; JANDREY, P. E.; SCHWANTES, D.; GONÇALVES, J. A. C.. Caracterização, classificação e destinação de resíduos da agricultura. Scientia Agraria Paranaensis, v.11, n.4, p.33-43, 2012. DOI: http://dx.doi.org/10.1818/sap.v11i4.5858

SARTORI, S. B.; FERREIRA, L. F. R.; MESSIAS, T. G.; SOUZA, G.; POMPEU, G. B.; MONTEIRO, R. T. R.. Pleurotus biomass production on vinasse and its potential use for aquaculture feed. Mycology, v.6, p.71-80, 2015. DOI: http://doi.org/10.1080/21501203.2014.988769

SEIXAS, L.; GIMENES, L.; FERNANDES, N. R. C.. Tratamento da vinhaça por adsorção em carvão de bagaço de cana-deaçúcar. Química Nova, v.39, n.2, p.172-179, 2016. DOI: http://doi.org/10.5935/0100-4042.20160013
SEREJO, M. L.. Cultivo de microalgas com vinhaça digerida anaerobiamente. Dissertação (Mestrado em Saneamento Ambiental e Recursos Hídricos) - Universidade Federal de Mato Grosso do Sul, 2010.

SILVA, C. E. F.; ABUD, A. K. S.. Influence of manure concentration as inoculum in anaerobic digestion of vinasse. Acta Scientiarum, v.39, n.2, p.173-180, 2017. DOI: http://doi.org/10.4025/actascibiolsci.v39i2.34007

SILVA, G.. Avaliação das tecnologias de disposição de vinhaça de cana de açúcar quanto ao aspecto de desenvolvimento ambiental e econômico. Tese (Doutorado em Térmica e Fluidos) - Universidade de São Paulo, São Carlos, 2012.

SILVA, M. A. S.; GRIEBELER, N. P.; BORGES, L. C.. Uso de vinhaça e impactos nas propriedades do solo e lençol freático. Revista Brasileira de Engenharia Agrícola e Ambiental, v.11, p.108-114, 2007.

SILVA, P. M. A.; BONO, A. M.; PEREIRA, A. R.. Aplicação de vinhaça na cultura da cana-de-açúcar: Efeito no solo e na produtividade de colmos. Revista Brasileira de Engenharia Agrícola e Ambiental, v.18, n.1, p.38-43, 2014. DOI: http://dx.doi.org/10.1590/S1415-43662014000100006

SILVEIRA, E.. Vinhaça para gerar energia. Revista Pesquisa FAPESP, p.68-71, 2015.

SOUZA, Z. J.; AZEVEDO, P. F.. Geração de energia elétrica excedente no setor sucroalcooleiro: um estudo a partir das usinas paulistas. Revista de Economia e Sociologia Rural, v.44, n.2, p.179-199, 2006. DOI: http://doi.org/10.1590/S0103-20032006000200002

SYDNEY, E. B.; LARROCHE, C.; NOVAKA, A. C.; NOUAILLE, R.; SARMAC, S. J.; BRAR, S. K.; LETTI, L. A. J.; SOCCOL, V. T.; SOCCOL, C. R.. Economic process to produce biohydrogen and volatile fatty acids by a mixed culture using vinasse from sugarcane ethanol industry as nutrient source. Bioresource Technology, v.159, n.1, p.380-386, 2014. DOI: http://dx.doi.org/10.1590/S1415-43662014000100006

VASCONCELOS, R. F. B.; CANTALICE, J. R. B.; SILVA, J. A. N. OLIVEIRA, V. S.; SILVA, Y. J. A. B.. Limites de consistência e propriedades químicas de um Latossolo amarelo distrocoeso sob aplicação de diferentes resíduos da cana-de-açúcar. Revista Brasileira de Ciência do Solo, v.34, n.3, p.639-648, 2010.

VIEIRA, M. C. A.; LIMA, J. F.; BRAGA, N. M.. Setor sucroalcooleiro brasileiro: evolução e perspectivas. 2007.

VUKOVIĆ, A. P. D.; MOJOVIĆ, V. L.; SEMENČENKO, V. V.; RADOSAVLJEVIC, M. M.; PEJIN, D. J.; KOCIC-TANACKOV, S. D.. Effective valorisation of distillery stillage by integrated production of lactic acid and high quality feed. Food Research International, v.73, p.75-80, 2015. DOI: http://doi.org/10.1016/j.foodres.2014.07.048

WILKIE, A. C.; RIEDESEL, K. J.; OWENS, J. M.. Stillage characterization and anaerobic treatment of ethanol stillage from conventional and cellulosic feedstocks. Biomass \& Bioenergy, v.19, n.2, p.63-102, 2000. DOI: http://doi.org/10.1016/S0961-9534(00)00017-9 
ZAZYKI, M. A. D.; ALMEIDA, V. P.; SANTOS, L. R..

Bioeletricidade: uma alternativa de complementaridade da matriz energética brasileira (bagaço e palha da cana-deaçúcar). In: FÓRUM INTERNACIONAL ECOINOVAR, 5; CONFERÊNCIA INTERNACIONAL DE SUSTENTABILIDADE E INOVAÇÃO, 1. Anais. Santa Maria, 2016.
ZOLIN, C. A.; PAULINO, J.; BERTONHA, A.; FREITAS, P. S. L.; FOLEGATTI, M. V.. Estudo exploratório do uso da vinhaça ao longo do tempo. I. Características do solo. Revista Brasileira de Engenharia Agrícola e Ambiental, v.15, n.1, p.22-28, 2011.

A CBPC - Companhia Brasileira de Produção Científica (CNPJ: 11.221.422/0001-03) detém os direitos materiais desta publicação. Os direitos referem-se à publicação do trabalho em qualquer parte do mundo, incluindo os direitos às renovações, expansões e disseminações da contribuição, bem como outros direitos subsidiários. Todos os trabalhos publicados eletronicamente poderão posteriormente ser publicados em coletâneas impressas sob coordenação da Sustenere Publishing, da Companhia Brasileira de Produção Científica e seus parceiros autorizados. Os (as) autores (as) preservam os direitos autorais, mas não têm permissão para a publicação da contribuição em outro meio, impresso ou digital, em português ou em tradução. 